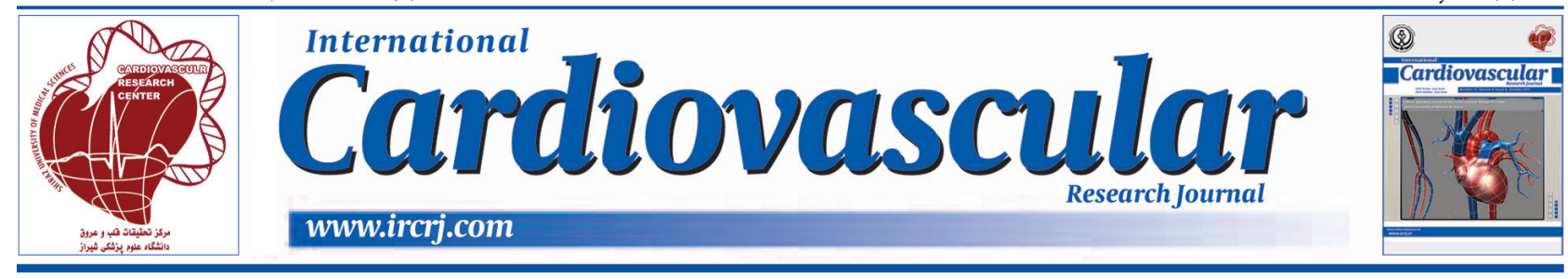

\title{
Epidemiological Characteristics and Clinical Outcome of Syncope in Children; A Report from Shiraz, Iran
}

\author{
Hamid Amoozgar, ${ }_{1}^{1}$ Nahid Homayoon, ${ }^{2}$ Gholamhossein Ajami, ${ }_{1}^{1}$ Mohammad Borzouee, ${ }^{1}$ Sirous \\ Cheriki, ${ }^{1}$ and Mohammadreza Edraki ${ }^{1, *}$
}

${ }^{1}$ Cardiovascular and Neonatology Research Center, Shiraz University of Medical Sciences, Shiraz, IR Iran

${ }^{2}$ Department of Pediatrics, Shiraz University of Medical Sciences, Shiraz, IR Iran

\begin{tabular}{l}
\hline A R T I C L E I N F O \\
Article Type: \\
Research Article \\
\hline
\end{tabular}

Article History:

Received: 21 Nov 2014

Revised: 08 May 2015

Accepted: 14 Jun 2015

\section{Keywords}

Child

Tilt-Table Test

Syncope

Therapy

\begin{abstract}
A B S T R A C T
Background: Syncope is a common problem among children.

Objectives: This cross-sectional study aimed to determine the epidemiological characteristics of children with syncope and clarify the outcome of managements in Imam Reza Pediatrics Cardiology Clinic affiliated to Shiraz University of Medical Sciences, the main referral center for pediatric patients with syncope in south of Iran.

Patents and Methods: This cross-sectional, descriptive-analytical study was conducted on all the children referred with transient loss of consciousness and positive head up tilt test. A total of 243 children (132 girls and 111 boys) were recruited from April 2007 to April 2013. The patients' treatment outcomes were determined through telephone interviews. All the statistical analyses were performed using the SPSS statistical software (version 16.0). Besides, $\mathrm{P}<0.05$ was considered to be statistically significant.

Results: The majority of the patients were female (54.3\% vs. $45.7 \%)$. In addition, the mean age at the first episode of syncope was $13.02 \pm 3.9$ years and $14.8 \%$ of the patients had positive family history of syncope. The mean duration of follow-up was $4.2 \pm 3.41$ years. Besides, breath holding spell history was positive in $13.6 \%$ of the patients. Medical treatment was done for $76.5 \%$ of the patients (96.7\% propranolol and $3.3 \%$ atenolol). Increase of salt and fluid intake and physical maneuvers were performed for management of syncope in $75.3 \%$ and $30.9 \%$ of the patients, respectively. During follow-up, $66.7 \%$ of the patients did not experience any syncope episodes at all. Among the patients, 33.3\% were referred by neurologists, while $66.7 \%$ had self-referred or referred by pediatricians or family practitioners. Moreover, $80.2 \%, 8.6 \%$, and $6.2 \%$ of the syncope cases were mixed type, inodeppressive, and choronodeppressive, respectively. Furthermore, 35.8\% of the tilt tests were positive with nitroglycerin consumption. Also, $11.1 \%$ of the patients had asystole $>3$ seconds during syncope.

Conclusions: This study indicated that similar to other populations, syncope was more prevalent among girls in our area. Additionally, the most common cause was mixed type of vasovagal syncope. Medical therapy along with offering the patients to increase water and salt intake and do counter pressure physical maneuvers were effective in reduction of the recurrence of syncope.
\end{abstract}

Implication for health policy/practice/research/medical education:

This study implicated in care of children with syncope.

\section{Background}

Syncope is a symptom in which transient and abrupt loss

*Corresponding author: Mohammadreza Edraki, Department of Pediatrics, Nemazee Hospital, Shiraz, Iran, PO Box: 7193711351. Cellphone: +989171209908, Fax: +98-7116474298

E-mail:edrakidr@yahoo.com of consciousness and postural tone occurs due to a period of inadequate cerebral nutritional delivery. The event is brief, is self-limited, and resolves spontaneously and completely without medical intervention. The most common cause of syncope is a transient fall of systemic arterial pressure to 
below the minimum level needed to sustain cerebral blood flow (1-3). Syncope is also a common pediatric problem. In total, $15-50 \%$ of children experience a syncopal episode by the age of 18 years and it affects $15-25 \%$ of children and adolescents. In the pediatric age group, syncope accounts for less than $1 \%$ of emergency department visits.

Syncope incidence peaks between the ages of 15 and 19 years for both sexes, but there appears to be a female predominance. Before the age of 6 years, syncope is unusual, except for the setting of seizures, breath-holding spells, and cardiac arrhythmias $(4,5)$.

The etiology of syncope can be divided into lifethreatening and benign causes. Life threatening conditions cause syncope by sudden decrease in cardiac output. The most common life-threatening causes of syncope include primary electrical disturbances (electrophysiological abnormalities, such as congenital long QT syndrome, Brugada syndrome, catecholaminergic polymorphic ventricular tachycardia, preexcitation syndrome, and congenital short QT syndrome) and structural heart disease (hypertrophic cardiomyopathy, coronary artery anomalies, arrhythmogenic right ventricular cardiomyopathy, valvular aortic stenosis, dilated cardiomyopathy, pulmonary hypertension, and acute myocarditis) (6-13). On the other hand, benign causes of syncope include vasovagal syncope (also known as neurocardiogenic or reflex syncope, the most common cause of syncope among children), breath holding spells, orthostatic hypotension, toxic exposure (either from decreased cardiac output [barbiturates, tricyclic antidepressants, and phenothiazines] or sudden loss of consciousness [cocaine, alcohol, marijuana, inhalants, and opiates]), and hypoglycemia $(5,14,15)$.

Pediatric causes of syncopal events are mostly benign, but syncope can also occur as a result of serious life-threatening causes with the potential for sudden death (particularly if it is recurrent or if there is a family history of sudden cardiac arrest). The most common causes of syncope in the pediatric age group are vasovagal episodes and orthostatic hypotension $(2,16,17)$.

\section{Objectives}

The present study aims to determine the epidemiological characteristics of syncope in children and clarify the outcome of management in our center as a main referral center in south of Iran.

\section{Patients and Methods}

This cross-sectional, descriptive-analytical study was conducted at Imam Reza pediatric cardiology clinic affiliated to Shiraz University of Medical Science, Shiraz, Iran, which is the main referral center in south of Iran. The study subjects were selected among the children aged less than 18 years who presented to Imam Reza cardiology clinic with the chief complaint of one or more episodes of transient loss of consciousness and positive head up tilt test from April 2007 to April 2013.

A questionnaire was completed by interviewing the patients or their parents through telephone. The questionnaire consisted of information about family history, past medical history, syncope history, syncope treatment (medical treatment, physical maneuvers, and education), patient's cooperation in the treatment, and follow-up. Among the 243 study patients, 23 ones who had incomplete charts or no contact numbers were excluded from the study.

\subsection{Tilt Testing}

The patients were asked to lie down in supine position on tilt bed for 15 minutes before tilting. Then, the bed was elevated at $60^{\circ}$ and the patients' heart rate, blood pressure, and symptoms were recorded. If syncope occurred, the tilt bed was returned to flat position. If syncope did not occur, the patients were kept in $60^{\circ}$ head up position for 20 minutes. After consumption of sublingual nitroglycerin, they were put back in supine position for another 15 minutes. Then, they were put in head up position for another 20 minutes.

The endpoint of tilt testing was induction of either reflex hypotension/bradycardia or delayed orthostatic hypotension associated with syncope or pre-syncope. When a reflex was induced, according to the predominance of vasodepressor or cardioinhibitory components, the responses were classified as cardioinhibitory, vasodepressor, or mixed $(18,19)$.

\subsection{Data Analysis}

All the statistical analyses were performed using the SPSS statistical software, version 16.0. The data were expressed as mean \pm standard deviation.

\section{Results}

This study was conducted on 243 patients with positive tilt table test results. The patients' ages ranged from 5 to 18 years, with the mean age of $13.023 .9 \pm$ years. The majority of the patients were female (132 girls (54.3\%) and 111 boys $(45.7 \%))$. In addition, $67.6 \%$ of the patients had their first syncope attack at $5-10$ years of age, $30 \%$ at $11-15$ years, and $2.4 \%$ at $16-20$ years.

All the patients presented to our clinic with a gap after their first syncope attack. Among the patients, $22.2 \%$ presented earlier than one month after their first syncope, $25.9 \%$ within 1 to 6 months, $11.1 \%$ within 6 to 12 months, $16 \%$ in more than 12 months, and $24.7 \%$ were not informative.

The study subjects' demographic features have been presented in Table 1. According to the results, $14.8 \%$ and $23.5 \%$ of the patients had positive family history of syncope and convulsion, respectively. In addition, 9.9\% of the patients had structural heart disease (mitral valve prolapse, ASD, and VSD). Besides, 8.6\% had convulsion, $7.4 \%$ had asthma, and 3.7\% had thyroid disease (hyper or hypothyroidism). Breath holding spell history was also positive in $13.6 \%$ of the patients. Moreover, $88.9 \%$ of the patients had 1 to 5 syncope attacks, $9.9 \%$ had 6 to 10 attacks, and1.2\% had more than 10 attacks before referring to the clinic and starting the management of syncope.

The pre-syncope symptoms have been shown in Table 2 . As the table depicts, $12.3 \%$ of the patients had no complaints or symptoms exactly before fainting. The most prevalent symptom was dizziness, which was reported in $63 \%$ of the patients. Other prevalent symptoms were light-headedness (48.1\%), headache (21\%), nausea (19.8\%), and palpitation $(17.3 \%)$. The conditions reported as a trigger for syncope in the patients have been presented in Table 3. Accordingly, prolonged standing was a positive trigger in $38.3 \%$, fatigue 


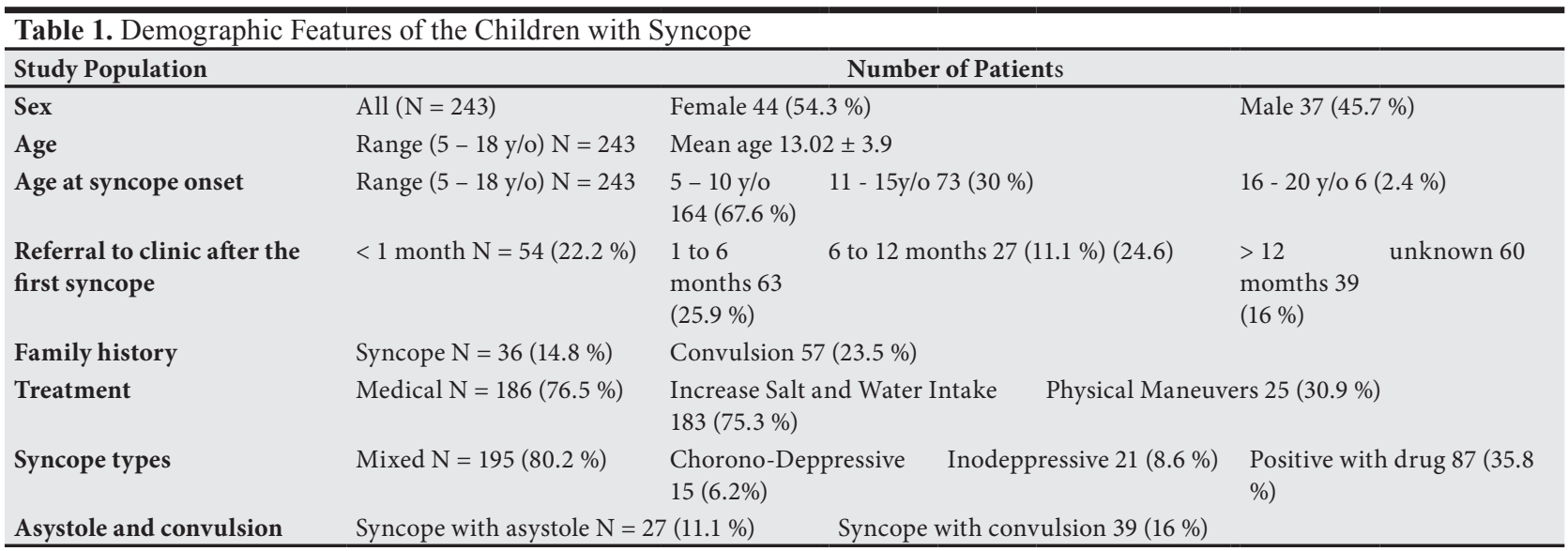

\begin{tabular}{lll}
\hline \multicolumn{2}{l}{ Table 2. The Prevalence of Pre-Syncope Symptoms in the Children with Syncope } & \\
\hline Symptoms & Symptom Positive Number (\%) & Symptom Negative Number (\%) \\
\hline Dizziness & $153(63 \%)$ & $90(37 \%)$ \\
Light-headedness & $117(48.1 \%)$ & $126(51.9 \%)$ \\
Headache & $51(21 \%)$ & $192(79 \%)$ \\
Nausea & $48(19.8 \%)$ & $195(80.2 \%)$ \\
Palpitation & $42(17.3 \%)$ & $201(82.7 \%)$ \\
Abdominal pain & $27(11.1)$ & $216(88.9 \%)$ \\
Dyspnea & $18(7.4 \%)$ & $225(92.6 \%)$ \\
Fever & $9(3.7 \%)$ & $234(96.3 \%)$ \\
No symptoms & $30(12.3 \%)$ & $213(87.7 \%)$ \\
\hline
\end{tabular}

\begin{tabular}{lll}
\hline \multicolumn{2}{l}{ Table 3. The Conditions Which Triggered Syncope in the Children } \\
\hline Conditions & Positive Number (\%) & Negative Number (\%) \\
\hline Prolonged standing & $93(38.3 \%)$ & $150(61.7 \%)$ \\
Fatigue & $63(25.9 \%)$ & $180(74.1 \%)$ \\
Hot weather & $48(19.8 \%)$ & $195(80.2 \%)$ \\
Venous puncture & $39(16 \%)$ & $165(68 \%)$ \\
Fear/phobia & $39(16 \%)$ & $165(68 \%)$ \\
Starvation & $27(11.1 \%)$ & $216(88.9 \%)$ \\
Changing position (orthostatic) & $24(9.9 \%)$ & $219(90.1 \%)$ \\
\hline
\end{tabular}

in $25.9 \%$, and hot environment in $19.8 \%$ of the patients.

The patients were treated with medication, physical maneuvers, and training for salt and liquid consumption and trigger avoidance. Among the patients, 62 (76.5\%) were given medication (96.7\% propranolol and 3.3\% atenolol). Among these patients, $48.3 \%$ received medication for 1 to 6 months, $20.9 \%$ for 7 to 12 months, $3.2 \%$ for 13 to 24 months, $11.2 \%$ for more than 24 months, and $16.1 \%$ had poor compliance and did not take their drugs. Additionally, 61 patients $(75.3 \%)$ increased their salt and fluid intake, 55 (67.9\%) did their routine sport activities, and $26(32.1 \%)$ reduced their sport activities.

All the patients were told to stand across the wall (tilt training) for 30 - 45 minutes. According to the results, 15.3\% of the patients stood across the wall for less than 10 minutes each day, $2.5 \%$ did it for more than 10 minutes, $12.3 \%$ did it on and off, and $66.7 \%$ did not do it at all. The other maneuver was leg muscle contraction while standing, which was advised to all the patients. This maneuver was done by $30.9 \%$ of the patients, but was not done by $69.1 \%$. Head elevation was also done only by $12.3 \%$ of the patients while sleeping.

The mean duration of follow-up was $4.23 .41 \pm$ years. During follow-up, $66.7 \%$ of the patients had no, $29.6 \%$ had $1-5,2.5 \%$ had $6-10$, and $1.2 \%$ had more than 10 syncope episodes. Moreover, 53.1\%, 29.6\%, and 17.3\% of the patients claimed improvement, relative improvement, and no improvement in their dizziness, respectively.

Among the patients, $33.3 \%$ were referred by neurologists and the remaining $66.7 \%$ were self-referred or referred by pediatricians or family practitioners. The results also showed that $80.2 \%$ of the cases were mixed type, $8.6 \%$ were inodeppressive, and $6.2 \%$ were choronodeppressive. Among the tilt tests, $35.8 \%$ were positive with nitroglycerin consumption and $64.2 \%$ were positive without drugs. Moreover, $11.1 \%$ of the patients had asystole during syncope, $88.9 \%$ had syncope without a systole, and $16 \%$ had convulsion during the tilt test. The onset of syncope after starting tilt testing ranged from 1 to 20 minutes. Out of the patients, $22.2 \%$ had syncope within $1-5$ minutes, 25.9 within 6 - 10 minutes, $19.8 \%$ within 11 - 15 minutes, and $8.6 \%$ within $16-20$ minutes after starting the test.

\section{Discussion}

Syncope is a common problem among children. The results of the present study showed that syncope was 
more prevalent in females. Chen Li et al. also claimed that among the 888 patients with syncope, 471 (53.0\%) were female and $417(47.0 \%)$ were male. Similar results were also obtained by Anderson et al. and Yilmaz et al. (F:M, 70.1:50.3 and 63.1:36.8). Similarly, Massin et al. claimed that in the 226 pediatric patients visited in their emergency department because of a syncopal event (mean age: 10.8 \pm 3.6 years), the male/female ratio was 95:131 (15, 20-22). All the above-mentioned studies revealed the increased female prevalence of syncope in adolescents.

In the current study, $88.9 \%$ of the patients had 1 to 5 syncope attacks before referring to the clinic and $25.9 \%$ presented earlier than one month after their first syncope attack. Anderson et al. conducted a study on 113 patients among whom, $71 \%$ had less than 3 syncope episodes, 19\% had 3 to 6 episodes, and $10 \%$ had more than 6 episodes. Out of these patients, $32 \%$ presented within a month after their first episode and $62 \%$ presented within 6 months after their first episode. The results of that study were similar to those of the present one (23).

In our study, $8.6 \%$ of the patients had positive history of convulsion and $16 \%$ had convulsion during the tilt test. Yilmaz et al. assessed 19 patients with transient loss of consciousness. They reported that $32 \%$ of the patients had history of limb movements of either tonic or myoclonic pattern (22).

In the present study, the conditions that triggered syncope were prolonged standing (38.3\%), fatigue (25.9\%), hot weather $(19.8 \%)$, venous puncture (16\%), fear/phobia (16\%), starvation (11.1\%), and changing position/orthostatic change (9.9\%). Li Chen et al. analyzed the association between the clinical manifestation and hemodynamic patterns of 629 children with orthostatic intolerance, either vasovagal syncope or postural orthostatic tachycardia syndrome. They concluded that complaint of syncope after motion with prodromal chest distress or palpitation and the concomitant symptom after a syncopal attack with the subsequent debilitation, dizziness, or headache were the most important variables in diagnosis of vasovagal syncope in children with orthostatic intolerance. In our study, dizziness (63\%), light-headedness (48.1\%), headache (21\%), and nausea (19.8\%) were more prevalent compared to palpitation (17.3). This is probably due to the difference between the study groups in the two studies. Our patients were cases with any type of syncope, but those of the study by Li Chen et al. were cases with orthostatic intolerance. In addition, Li Chen et al. considered both pre- and postsyncope symptoms, but we just took pre-syncope symptoms into account. Yilmaz et al. also evaluated 19 patients with transient loss of consciousness and found that $15.7 \%$ of the patients had abdominal pain during attacks. In our study, abdominal pain was found in $11.1 \%$ of the patients before attacks $(22,24)$. Ganzeboom et al. conducted a study on 253 female (64\%) and 124 male (31\%) medical students with a median age of 21 years. In that study, the circumstances mentioned by the students as triggers for syncope were warm environment (31\%), prolonged standing (27\%), pain $(25 \%)$, illness (18\%), alcohol consumption (13\%), emotion (11\%), venous puncture $(10 \%)$, standing $(8 \%)$, menstruation $(6 \%)$, insufficient food intake $(6 \%)$, fasting $(6 \%)$, fatigue $(5 \%)$, drugs (5\%), and tiredness (5\%). Providencia et al. studied 2047 young working adults or students with a mean age of
22 years. Out of these individuals, 2011 completed the study questionnaire. According to the results, syncope triggers included warm environment (22.3\%), fasting (20.8\%), emotion $(13.4 \%)$, venous puncture $(13.2 \%)$ prolonged standing $(11.9 \%)$, pain $(11.8 \%)$, after physical exercise (8.9\%), alcohol consumption (7.9\%), during physical exercise (7.4\%), illness $(4.5 \%)$, accident $(3.3 \%)$, drugs $(1.5 \%)$, and epileptic features $(1.5 \%)$. The results of all the three studies mentioned above demonstrated prolonged standing and hot weather as important triggers for syncope. Venous puncture also accounted for $10-16 \%$ of the triggers in these studies. Yet, fatigue was more prevalent among our patients, which could be due to the difference among the study populations' mean ages. Our subjects were children, while those of the studies by Ganzeboom and Providencia were young adults. Additionally, the median age of syncope was 13 years in our study, but 15 years in Ganzeboom's study $(24,25)$.

In the present study, medical and non-pharmacological treatment were both recommended to the patients. According to the results, $76.5 \%$ of the patients were given medication, with propranolol being the major drug prescribed for the patients. Besides, $75.3 \%$ of the patients increased their salt and fluid intake and $30.9 \%$ did physical maneuvers. During follow-up, $66.7 \%$ of the patients did not have any syncope episodes at all and $53.1 \%$ claimed that their dizziness had improved. Li et al. investigated syncope or pre-syncope episodes in 79 patients, consisting of 37 boys and 42 girls, with a mean age of $12.4 \pm 3.2$ years. In that study, most of the patients accepted non-pharmacological treatment (education and increasing fluid and salt intake) and only $15.4 \%$ accepted short-term pharmacological treatment ( $\beta$ blocker, diphenidol). During follow-up, the overall recurrence rate was $30.8 \%$, but most of the patients experienced less severe syncopal episodes and only had premonitory symptoms (26). Our study indicated that combination of beta-blocker therapy with increasing salt and water intake decreased the recurrence rate of syncope.

In the current study, $80.2 \%$ of the cases were mixed type, $8.6 \%$ were inodeppressive, and $6.2 \%$ were choronodeppressive. Lai et al. examined 79 patients below 18 years of age who underwent head up tilt test for evaluation of syncope or presyncope. Among the patients, $69 \%$ had mixed type, $28 \%$ had cardioinhibitory, $3 \%$ had vasodepressor, and 3.7\% had asystole syncope attacks (26). Yilmaz et al. also performed a study on 150 patients aged between 8 and 18 years who were referred to their clinic due to syncope. Their study results demonstrated that tilt test was positive in 97 patients. Besides, 49.4\%, 35\%, and $15.4 \%$ of the patients had mixed, vasodepressor, and cardioinhibitory syncope attacks, respectively (27).

In the current study, onset of syncope after starting tilt testing ranged from 1 to 20 minutes. Lin J et al. examined 174 children with a mean age of $11.3 \pm 2.8$ years with unexplained syncope. The patients underwent head-up tilt test, and positive response appearance time was $15.1 \pm 14.0$ minutes at $60^{\circ}$ for vasovagal syncope children (28).

The present study findings demonstrated that $8.6 \%$ of the patients had convulsion. Wang $\mathrm{C}$ et al. performed a study on 2377 cases with syncope aging 2 - 78 years $(18.57 \pm 14.36)$. Among the patients, 1719 were younger than 18 years. All 
the patients underwent head up tilt test. The results indicated that $3.74 \%$ of the cases (more adults $(62.92 \%)$ compared to children (37.08\%)) experienced syncope with convulsion symptoms during head up tilt test. In comparison to our study, Wang's study patients developed convulsion less, which may be due to the fact that Wang's study subjects included both children and adults (29).

In the present study, $64.2 \%$ of the tilt tests were positive without drugs and $35.8 \%$ were positive with nitroglycerin consumption. Foglia-Manzillo et al. studied 164 patients with a mean age of $13 \pm 3$ years. In that study, tilt test was done for 161 patients with and without sublingual nitroglycerin consumption. During the unmedicated phase, $8 \%$ of the patients had syncope. After drug stimulation, a positive response occurred in 88 patients (55\%), giving a 63\% global positivity rate for the test. Our study findings also showed that drug administration made the test more sensitive (30).

\section{Acknowledgements}

The present article was extracted from a dissertation approved by Shiraz University of Medical Sciences, Shiraz, Iran. The authors would like to thank Dr. Nasrin Shokrpour at Center for Development of Clinical Research of Nemazee Hospital for editorial assistance.

\section{Authors' Contribution}

Hamid Amoozgar, MD: Concept/design, data collection, data analysis/interpretation, drafting manuscript, critical review and revision of manuscript, approval of final version. Analysis/interpretation, critical review and revision of manuscript, approval of final version. Nahid Homayoon, MD: Concept/design, data analysis/ interpretation, critical review and revision of manuscript, approval of final version. Gholamhossein Ajami, MD: Concept/design, data analysis/ interpretation, critical review and revision of manuscript, approval of final version. Mohammad Borzoee, MD: Concept/design, data analysis/ interpretation, critical review and revision of manuscript, approval of final version. Sirous Cheriki, MD: Concept/design, data analysis/ interpretation, critical review and revision of manuscript, approval of final version. Mohammad Reza Edraki, MD: Concept/design, correspondence, data analysis/interpretation, critical review and revision of manuscript, approval of final version.

\section{Financial disclosure}

There is no financial disclosure.

\section{Funding/Support}

This work was supported by the Research Vice chancellor of Shiraz University of Medical Sciences.

\section{References}

1. Brignole M, Benditt DG. Chapter 1, Syncope: Definition, Terminology, and Classification. Syncope: An evidence-based approach. 1st ed: Springer Science \& Business Media; 2011. pp. 5-12.

2. Shah SS, Ludwig S. Chapter 18, Syncope. In: McGraw-Hill, editor. Symptom-Based Diagnosis in Pediatrics [Internet]. 1 st ed. McGraw-Hill Professional Publishing; 2013.

3. Judith E, Tintinalli J, Stapczynski S, John Ma O, David M, Cline R, et al. Chapter 56, Syncope. The American Tintinalli's Emergency Medicine: A Comprehensive Study Guide [Internet]. 7th ed. McGraw-Hill Professional Publishing; 2011.
4. Moodley M. Clinical approach to syncope in children. Semin Pediatr Neurol. 2013;20(1):12-7.

5. Strange GR, Ahrens WR, Schafermeyer RW, Wiebe RA. Pediatric Emergency Medicine, 3e. Chapter;

6. Alexander ME, Berul CI. Ventricular arrhythmias: when to worry. Pediatr Cardiol. 2000;21(6):532-41.

7. Basso C, Corrado D, Rossi L, Thiene G. Ventricular preexcitation in children and young adults: atrial myocarditis as a possible trigger of sudden death. Circulation. 2001;103(2):269-75.

8. Gillette PC, Garson A, Jr. Sudden cardiac death in the pediatric population. Circulation. 1992;85(1 Suppl):I64-9.

9. Mivelaz Y, Di Bernardo S, Pruvot E, Meijboom EJ, Sekarski N. Brugada syndrome in childhood: a potential fatal arrhythmia not always recognised by paediatricians. A case report and review of the literature. Eur J Pediatr. 2006;165(8):507-11.

10. Probst V, Denjoy I, Meregalli PG, Amirault JC, Sacher F, Mansourati $\mathrm{J}$, et al. Clinical aspects and prognosis of Brugada syndrome in children. Circulation. 2007;115(15):2042-8.

11. Probst V, Evain S, Gournay V, Marie A, Schott JJ, Boisseau P, et al. Monomorphic ventricular tachycardia due to Brugada syndrome successfully treated by hydroquinidine therapy in a 3-year-old child. J Cardiovasc Electrophysiol. 2006;17(1):97-100.

12. Schimpf R, Wolpert C, Gaita F, Giustetto C, Borggrefe M. Short QT syndrome. Cardiovasc Res. 2005;67(3):357-66.

13. Skinner JR, Chung SK, Nel CA, Shelling AN, Crawford JR, McKenzie N, et al. Brugada syndrome masquerading as febrile seizures. Pediatrics. 2007;119(5):e1206-11.

14. Massin MM, Bourguignont A, Coremans C, Comte L, Lepage P, Gerard P. Syncope in pediatric patients presenting to an emergency department. J Pediatr. 2004;145(2):223-8.

15. Onvlee-Dekker IM, De Vries AC, Ten Harkel AD. Carbon monoxide poisoning mimicking long-QT induced syncope. Arch Dis Child. 2007;92(3):244-5

16. Lewis DA, Dhala A. Syncope in the pediatric patient. The cardiologist's perspective. Pediatr Clin North Am. 1999;46(2):205-19.

17. Pratt JL, Fleisher GR. Syncope in children and adolescents. Pediatr Emerg Care. 1989;5(2):80-2.

18. Abe H, Benditt DG, Decker WW, Grubb BP, Sheldon R, Shen WK. Guidelines for the diagnosis and management of syncope (version 2009). European Heart Journal. 2009;30:2631-71.

19. Cooper N. Tilt Testing informayion and protocols for technicians and doctors June. LeedsTeaching Hospitals NHS trust. June 2008.

20. Anderson JB, Czosek RJ, Cnota J, Meganathan K, Knilans TK, Heaton PC. Pediatric syncope: National Hospital Ambulatory Medical Care Survey results. J Emerg Med. 2012;43(4):575-83.

21. Chen L, Wang C, Wang H, Tian H, Tang C, Jin H, et al. Underlying diseases in syncope of children in China. Med Sci Monit. 2011;17(6):PH49-53.

22. Yilmaz S, Gokben S, Levent E, Serdaroglu G, Ozyurek R. Syncope or seizure? The diagnostic value of synchronous tilt testing and videoEEG monitoring in children with transient loss of consciousness. Epilepsy Behav. 2012;24(1):93-6.

23. Anderson JB, Czosek RJ, Knilans TK, Marino BS. The effect of paediatric syncope on health-related quality of life. Cardiol Young. 2012;22(5):583-8.

24. Ganzeboom KS, Colman N, Reitsma JB, Shen WK, Wieling W. Prevalence and triggers of syncope in medical students. Am J Cardiol. 2003;91(8):1006-8. A8.

25. Providencia R, Silva J, Mota P, Nascimento J, Leitao-Marques A. Transient loss of consciousness in young adults. Int J Cardiol. 2011;152(1):139-43.

26. Lai WT, Chen MR, Lin SM, Hwang HK. Application of head-up tilt table testing in children. J Formos Med Assoc. 2010;109(9):641-6.

27. Yılmaz ST, Binnetoğlu K, Babaoğlu K, Altun G. Predictors of vasovagal syncope recurrence in children and adolescents and value of head-up tilt table test. Anadolu Kardiyol Derg. 2013;13:688-94.

28. Lin J, Wang Y, Ochs T, Tang C, Du J, Jin H. Tilt angles and positive response of head-up tilt test in children with orthostatic intolerance. Cardiol Young. 2015;25(1):76-80.

29. Wang C, Li W, Wu L, Lin P, Li F, Luo H, et al. [Clinical characteristics and treatment of 89 patients with head-up tilt table test induced syncope with convulsion]. Zhong Nan Da Xue Xue Bao Yi Xue Ban. 2013;38(1):70-3.

30. Foglia-Manzillo G, Giada F, Fteita N, Nessi I, Santarone M, Raviele A. Tilt testing potentiated with sublingual nitroglycerin in children with unexplained syncope. Eur Heart J. 2007;28(21):2605-9. 